\title{
Implementation of Simulation in the Design of Robotic Production Systems
}

\author{
Naqib Daneshjo ${ }^{1}$, Peter Malega ${ }^{2}$, Jana Hlubeňová ${ }^{3}$, Pavol Štuller ${ }^{1}$ \\ ${ }^{1}$ University of Economics in Bratislava, Faculty of Commerce, Dolonozemská cesta 1, \\ 85235 Bratislava 5, Slovak Republic \\ ${ }^{2}$ Technical university of Kosice, Faculty of Mechanical Engineering, Letná 9, \\ 04200 Košice, Slovak Republic \\ ${ }^{3}$ L.E.F., spol. S.r.o., Trieda SNP1B , 04011 Košice, Slovak Republic
}

\begin{abstract}
The paper deals with the implementation of new approaches in modelling and simulation of production systems. Methodology was created based on the performed analyses using scientific procedures, which enables to model and subsequently simulate the required functionality of the robotized production system in a virtual environment. The thesis presents development trends focused on graphical support tools, animation and virtual methods and techniques of production system simulation and selected methods of processing are based on the performed analysis. Based on the theory of knowledge and expert systems and known methods of modelling and simulation, the focus of the work is to implement new approaches to the methodology of modelling and simulation of robotic / manipulation workplaces. The methodology developed uses proven approaches and for the sake of simplicity it effectively uses a system of dialog windows. The results of experiments for verification of methodology on real example are presented in this paper.
\end{abstract}

Keywords - simulation system, robot station, production system, modelling and simulation.

DOI: 10.18421/TEM111-22

https://doi.org/10.18421/TEM111-22

Corresponding author: Daneshjo Naqib,

Faculty of Commerce of the University of Economics in Bratislava, 85235 Bratislava 5, Slovak Republic.

Email: daneshj047@gmail.com

Received: 03 December 2021.

Revised: 18 January 2022.

Accepted: 24 January 2022.

Published: 28 February 2022.

(cc)BY-NC-ND (C) 2022 Daneshjo Naqib et al; published by UIKTEN. This work is licensed under the Creative Commons Attribution-NonCommercial-NoDerivs 4.0 License.

The article is published with Open Access at https://www.temjournal.com/

\section{Introduction}

Today, market demands are changing rapidly. The most important strategic weapon of the company is adaptation of manufacturers to customer's requirements. One of the main parts of computer integrated production is a flexible manufacturing system. The optimal use of critical features of production systems, such as increasing productivity and quality of production, reducing material and energy intensity of production, shortening production lead times, only emphasizes the importance of a systematic and comprehensive approach to designing production systems.

The aim of this paper is to extend the methodology for modelling and simulation verification of robotic or manipulation workplaces using virtual reality environment. The transition from design to implementation requires the use of modern scientific methods and available technical tools.

The present work aims to answer the question "how to transform from a robotized workplace project to its implementation into a real enterprise using virtual reality modelling and simulation", what steps need to be taken for a smooth implementation, and etc. The proposed methodology should provide answers to these questions.

\section{Methodology of Modelling and Simulation of Robotic / Manipulation Systems}

To create the methodology, it is necessary to define the relevant terms that will be used (Figure 1):

- Design methodology: Summary of procedures and methods that define what is done in the creation process.

- Methodology of draft: It determines what needs to be done at a stage of the proposal and what approaches need to be followed.

- Technics: They determine how to proceed in solving the proposal. 
- Instruments: They are the tools to carry out an activity.

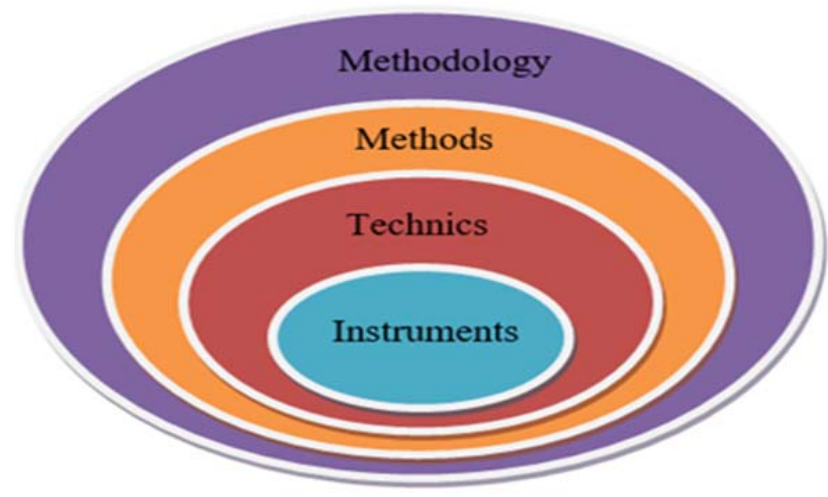

Figure 1. Interconnection between the various means of the proposal

The methods used in designing the modelling and simulation methodology of manipulation and robotized workplaces in a virtual reality environment are standard scientific methods and approaches that are not explicitly highlighted in the work. This section provides only a brief description and explanation of the basic methods that are most used in the creation of this work [8]. The analytical method was used to break down a phenomenon, situation and knowledge so that relevant information could be obtained as needed.

The analytical method was used where it was necessary to carry out the analysis. The use of this method has been widely used in the development of the methodology [2]. The method has been implemented in several areas. It was applied in individual algorithms wherever it was necessary to analyse the situation in order to obtain a correct answer. In Figure 2, blocks (blue blocks) showing the areas where the analytical method was used are shown.

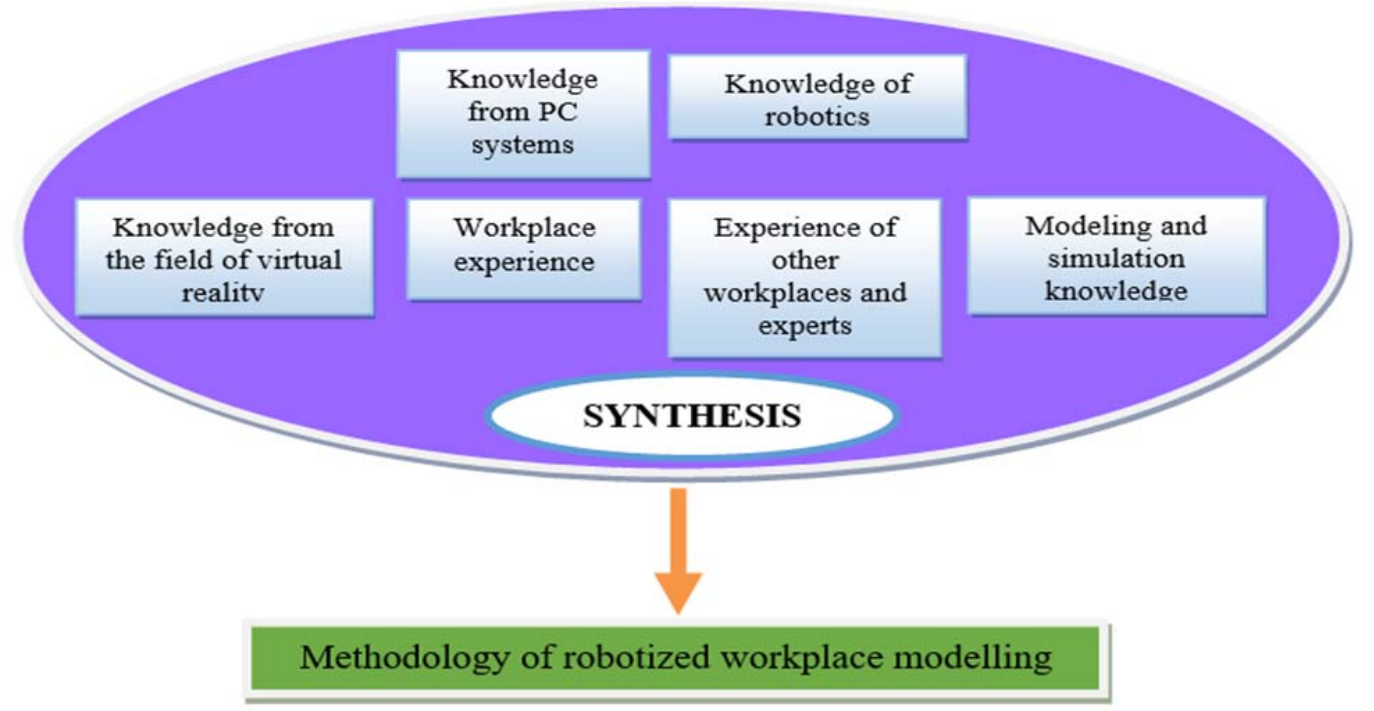

Figure 2. Areas of main application of the analytical method

The synthetic method (or synthesis) has been used to derive general principles from the relevant conclusions drawn. The synthesis is shown in Figure 2 in the purple section. The synthesis was realized in full extent in the work and its output is a proposed methodology. The correctness of the synthesis for complex problems can be checked comparatively, which was done when the correctness of the synthesis was verified based on own and mediated knowledge and experience [7].

The comparative method (or comparison) was used to compare the results and statements in the individual sections with other authors. The induction method (or induction) was used to draw general conclusions from individual cases. The deduction method (or deduction) has been used to derive specific cases from the general principles.
The principles of logic and logical thinking were applied in the solution. The underlying law of logic is that $\mathrm{A}$ cannot be $\mathrm{A}^{\prime}$ at the same time and under the same circumstances [3]. This law is applied in compound logical statements that are used in the work in expression, especially in algorithms.

\section{Results of Work - Creation of Algorithm}

The algorithm is an accurate guide for managing an activity. When creating an algorithm, the input and output conditions have to be precisely defined. The input and output condition were characterized by the problem that we need to solve. Certain requirements were imposed on the registration of conditions such as clarity. The whole created algorithm has to fulfil three basic properties [9]: 
- Determination: The operation of the algorithm has to be accurate and generally understandable.

- Bulkiness: The algorithm does not serve to solve one task.

- Resultivity: The algorithm will be used to solve any task and will stop after a finite number of steps. It has to give the desired result after stopping.

\subsection{Modelling Methodology}

The methodology for modelling is first introduced as a whole (i.e., a global view of the methodology), followed by further steps of the methodology in the subchapter. This provides an overall view. The proposed methodology is shown in Figure 3.

The individual steps of the methodology can be divided into three phases for better clarity. Each phase is dependent on the previous phase, so the modelling and simulation phase is not feasible without the input phase [5]. The output phase is not possible without the input, modelling and simulation phases. For clarity, the phases are also marked in colour with the letters "A", "B" and "C".

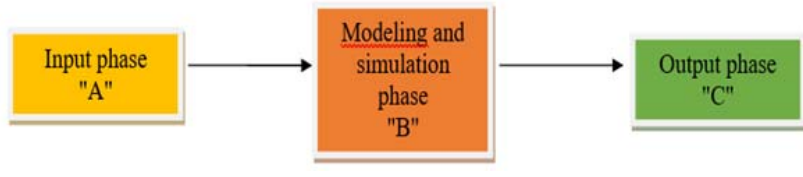

Figure 3. Methodology - phases

The first step is the entry phase "A". This step specifies what to model and how to use the model. Workplace requirements, customer requirements are identified, all input data are completed, and appropriate simulation software is selected.

The next phase is the modelling and simulation phase "B". This phase includes the area of positioning and defining spatial objects, then creating control structures and programming the robot, respectively the manipulator. The end point of this phase is the optimization of the designed and simulated workplace. The last phase is the output phase "C". This phase includes verification on real elements and implementation on the real workplace itself. At this stage, an inspection report, a return report and documentation of the workplace are also produced.

In Figure 4, some feedbacks between parts are not shown. These linkages are illustrated in the detailed design of the individual sections in the subchapters.
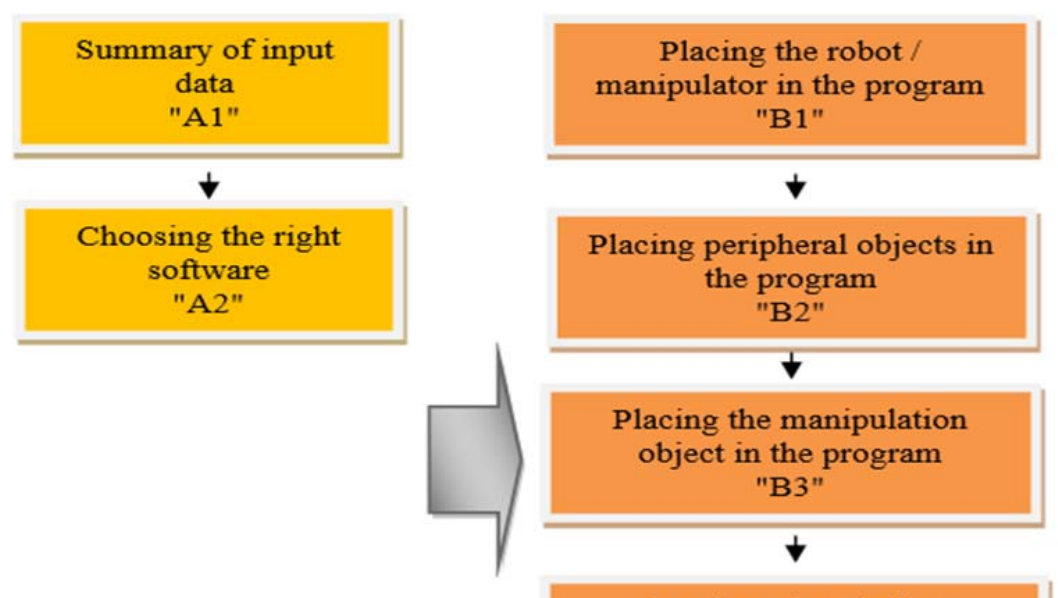

Creation of workplace

management structures "B4"

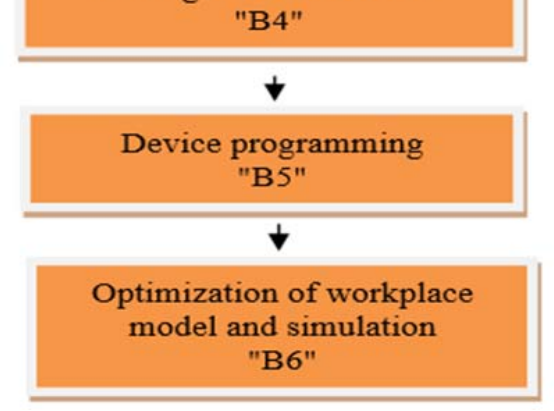

Figure 4. Methodology - general view

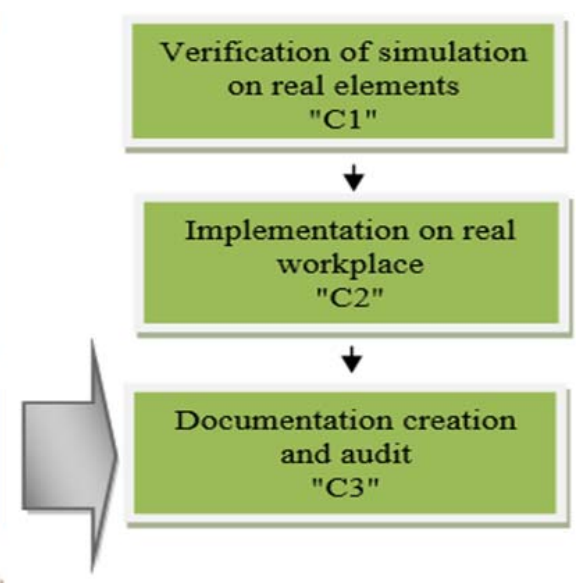




\subsection{Software Selection}

Currently, there are a large number of software tools on the market designed for modelling and simulation of the virtual factory. In this work, 13 available programs were compared. Due to the rapid development, this list and the proposed methodology for program selection has to be constantly supplemented and innovated. The methodology includes programs designed to simulate robotic workplaces, to simulate a virtual enterprise and also to simulate logistics production systems. The program selection was made to cover all the requirements for simulating logistics processes and virtual factories. The following software was monitored:

- Software for logistics: Arena: eM-Plant, Witness;

- Software for virtual enterprise: Cosimir Professional (CIROS Studio), Delmia-Quest, eM-Workspace;

- Software for robotized workplaces: Cosimir Robotics (CIROS Studio), Robot Studio, Easy Rob, Ropsim, Kuka Sim, Fanuc Sim Pro, Workspace.

Based on the analysis of the programs, a methodological procedure was created. All logistics programs enabled import of CAD formats, $\mathrm{C}++$ programming, real-time simulation, runtime error correction, statistical analysis (in the form of tables, graphs, time calculation, cost calculations) are intended for production design, warehouse management, handling and distribution, etc. [12]. In principle, they differed only in the working environment $-2 \mathrm{D}$ respectively $3 \mathrm{D}$ environment and demanding work with the program [4], [11]. The virtual enterprise simulation programs also include the robotized workplace itself, so they were considered together with the programs designed to simulate the robotized workplace [1], [10]. All had the opportunity to model and simulate in $3 \mathrm{D}$, model kinematic structure and mechanisms, display cyclic times, library of application objects, import CAD formats, detailed graphical processing, real-time simulation, eliminate errors during the program, process optimization for production stage, possibility off-line robot programming, collision detection, the library contained robots, effectors, conveyors and other equipment, etc.

The programs differed in the possibility to simulate different types of robots (Kuka, ABB, Fanuc, Mitsubishi, Reis and others), in IRL and VBA programming, $\mathrm{NC}$ and $\mathrm{CNC}$ machine programming [6]. Furthermore, the difference of programs consisted in the possibility of dynamic and static analysis, the possibility of export to CAD, export of MPEG animations, programming in $\mathrm{C}++$ and others, the possibility of calibration, time calculation, HTML reports, etc. As part of our research, we tried to find answers to key questions (Figure 5; Methodology for program selection):

- Does the simulation result in a robotized workplace? Should the simulation result in a robotized workplace, a handling workplace, or other?

Yes - only robotized workplace will be the result, programs - 2, 3, 4, 7, 8, 9, 10,11, 12, 13 can be counted, respectively; change of logistic structure. Suitable software - 1, 5, 6 .

No - the simulation will not result in a robotized workplace; it is only necessary to optimize another non-robotic workplace; change of logistic structure. Suitable software - 1, 5, 6 .

- Is the modelled workplace modelled in 3D? In some cases, it is sufficient to model the workplace only $2 \mathrm{D}$, unless it is necessary in $3 \mathrm{D}$.

Yes - 3D modelling is required. Software compliant - 5, 6 .

No - 3D modelling is not necessary, 2D is enough. Software compliant - 1, 5 .

- Should the complexity of work with the program be easy?

At this point, 2 programs were compared in terms of their labour intensity. It is a subjective comparison, but most of the students studied rated the program as more demanding than the other.

Yes - 3D modelling is required. Compliant with software - 1 .

No - No need to model 3D, just 2D. Software compliant -5 .

- Does the program support the export of animations in MPEG?

Yes - The program supports export of animations in MPEG. Software compliant - 2, 3, 4, 12, 13.

No - The program does not support the export of animations in MPEG. Software compliant - 8, 9, 10,11 .

- Should the program have a static and dynamic analysis?

Yes - The program has static and dynamic analysis. Software Compliant - 8 .

No - The program does not have static and dynamic analysis. Software compliant - 7, 9, 10, 11.

- Does the program support calibration?

Yes - The program supports calibration. Software Compliant - 11 .

No - The program does not support calibration. Compliant software - 7, 9, 10.

- Does the program support IRL programming?

IRL - Industrial Robot Language (defined by German standard DIN 66312).

Yes - The program supports IRL programming. Software compliant - 9 .

No - The program does not support IRL programming. Software compliant $-7,10$. 
- Is it necessary to simulate a KUKA robot? Yes - The KUKA robot will be simulated. Software Compliant - 10.

No - A robot other than KUKA will be simulated. Software compliant - 7.

- Does the program support the export of CAD formats?

Yes - You will need to export CAD formats. Software compliant - 2, 3, 4, 12.

No - No need to export CAD formats. Software Compliant - 13.

- Does the program support VBA programming?

Yes - The program supports VBA programming. Software Compliant - 12.
No - The program does not support VBA programming. Software compliant - 2, 3, 4 .

- Should PLC be simulated?

Yes - The PLC will be simulated. Software compliant $-2,4$.

No - PLC will not be simulated. Software compliant - 3 .

- Does the program support statistical analysis?

Yes - The program should support statistical analysis. The software complies - 4 .

No - The program does not need to support statistical analysis. Software compliant - 2 .

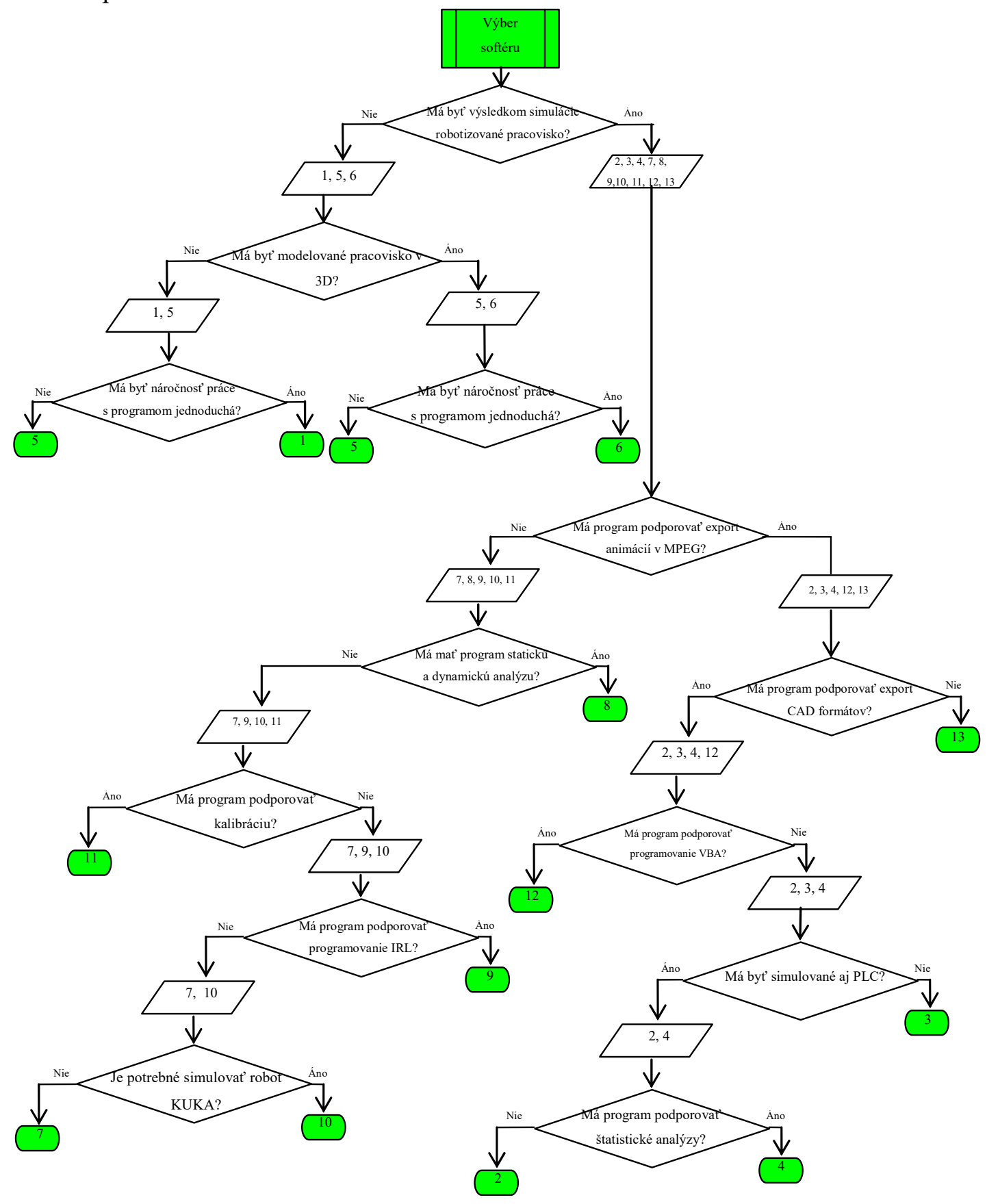

Figure 5. Methodology for program selection

1. Arena, 2. Cosimir Professional 3. Cosimir Robotics, 4. Delmia Quest, 5. eM-Plant, 6. Witness, 7. Robot Studio, 8. Easy Rob, 9. Ropsim, 10. Kuka Sim, 11. Fanuc Sim Pro, 12. Workspace, 13. eM- Workspace 


\section{Experimental Solution}

Figure 6 presents the layout of the workplace with the stations currently available and the stations being planned. The stations are spatially distributed around a conveyor (1) that provides material flow. It usually starts at station two, then continues through station three in the direction of the indicated arrows and ends either in the warehouse (9) or at the three exit stations $(10,11,12)$. The conveyor has individual ports from which the material can be transferred to individual stations or vice versa - from the stations to the conveyor. At present, the material flow can only take place between stations 7 and 12 in terms of station availability.

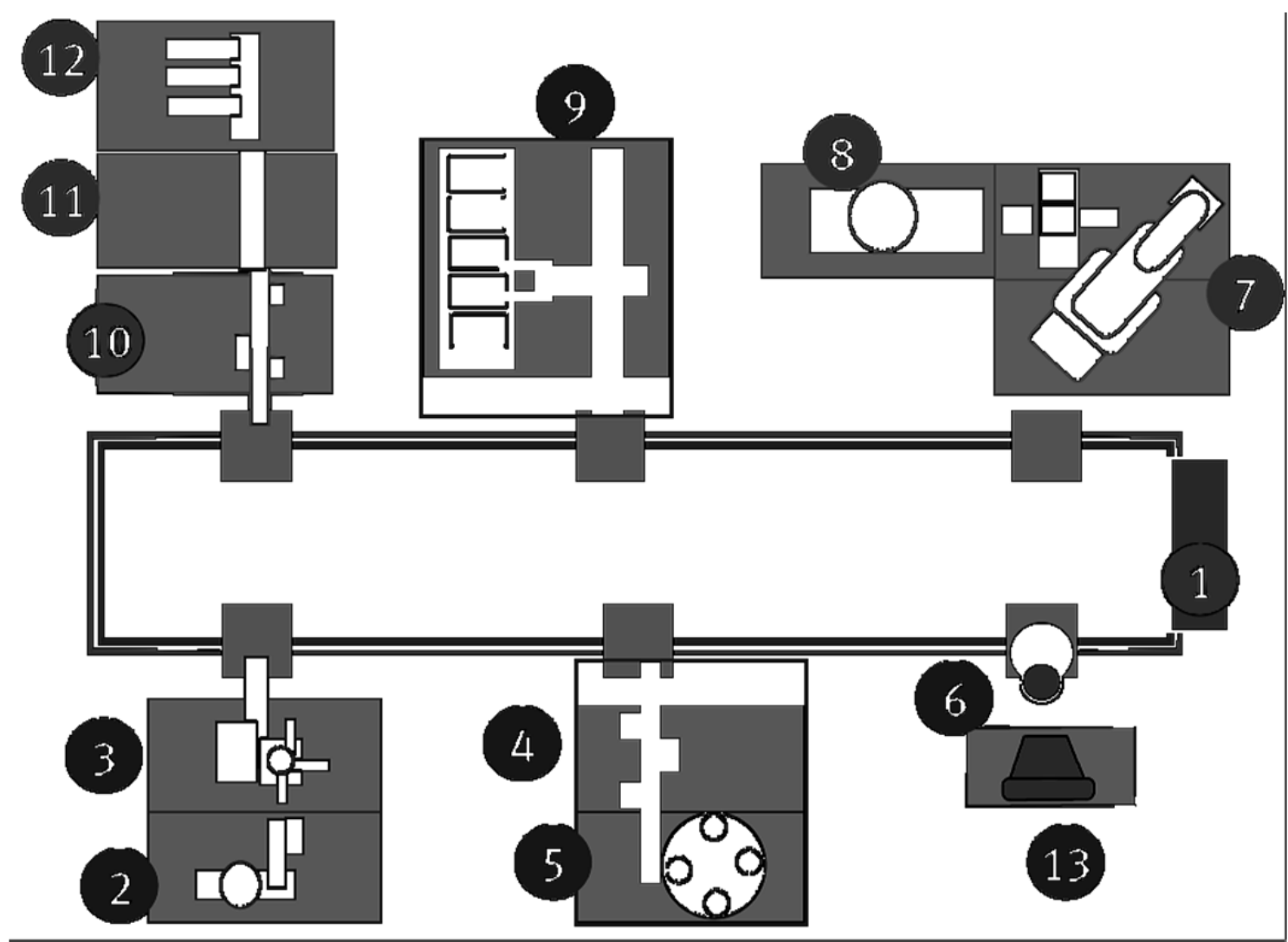

Available stations in the laboratory: 1. Conveyor System, 2. Distribution Station, 7. Assembly Station, 10. Handling station II, 11. Buffering Station, 12. Sorting Station,

Not yet available stations: 2. Distribution station, 3. Testing station, 4. Handling Station I, 5. Processing station, 6. Vision camera system, 8. Hydraulic Punch Station, 9. Storage station, 13. SCADA Control Station

Figure 6. Modular production system

The workplace was chosen to verify the proposed methodology. The "Robot" station consists of a 5axis MITSUBISHI RV2-AJ robot, its CR1 control unit and peripherals and elements mounted on an aluminium base. The station is designed for a specific assembly task. It includes mounting hole, gravity chute tray, two gravity vertical trays, and optical sensors to distinguish colour from reflection.

The robot is equipped with a multifunctional effector for gripping several kinds of components. The effector is controlled by pneumatic devices. The whole station is controlled by the CR1 robotic control unit. It supports the programming languages Melfa Basic IV and Movemaster Command [72].

On the aluminium base there are three cartridges that supply the individual components for the assembly process (pistons, springs, lids). They are operated electro-pneumatically and can be controlled directly from the CR1 or via FEC640 PLC control units. The individual tanks have integrated position and status sensors in the tanks.

In Figure 7 there are 2 stations, i.e., robot and assembly station. Together they form a unit that serves as a school model for the assembly of specific types of plastic components. 


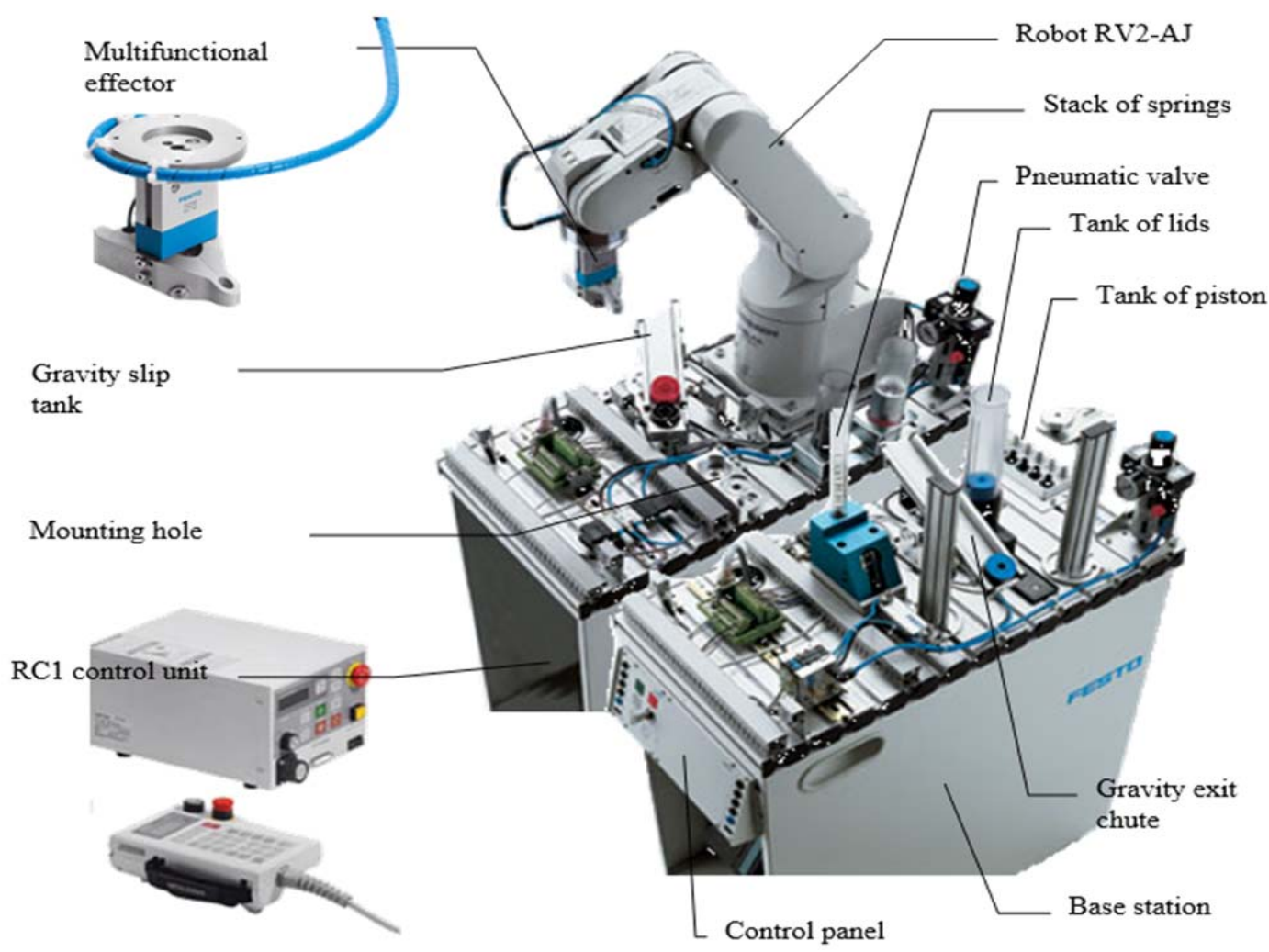

Figure 7. Robot station and assembly station

The components (Figure 8) differ in their colours and dimensions. There are three types of base rollers. The red and silver cylinders have the same dimensions and are fitted with black pistons, while the black cylinders have different heights and inner diameters, and the silver pistons are inserted.

After insertion of the pistons, the springs are mounted on the individual pistons and the lid is mounted on the top, which is fastened to the cylinder by pressing and rotating in exactly specified positions. The entire assembly takes place in the mounting well, where the cylinder base body is secured against rotational movement by means of a pin and subsequently brought, positioned and placed in the robot effector in a specified manner and then the lid.

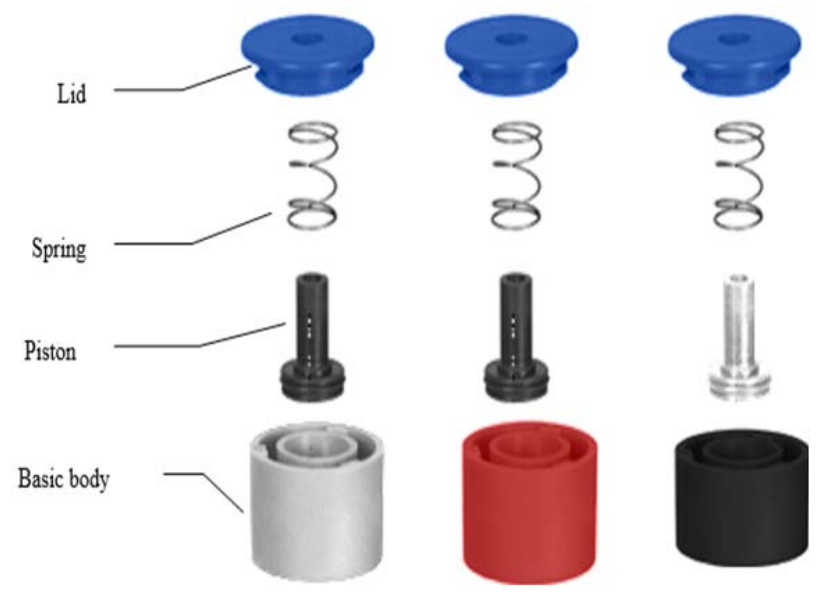

Figure 8. Mounted component

\subsection{Entering the Task}

Within the automation and control laboratory being built, various tasks were solved individually and as a whole. Several tasks also concern the robotized cell within the MPS production system. The robotized cell consists of a robot station and an assembly station, the inlet and outlet of these stations being handling objects located on the conveyor. On the robotized cell, the 4-component handling object is folded, the robot taking the roller from the conveyor and placing the finished composite part back on the conveyor.

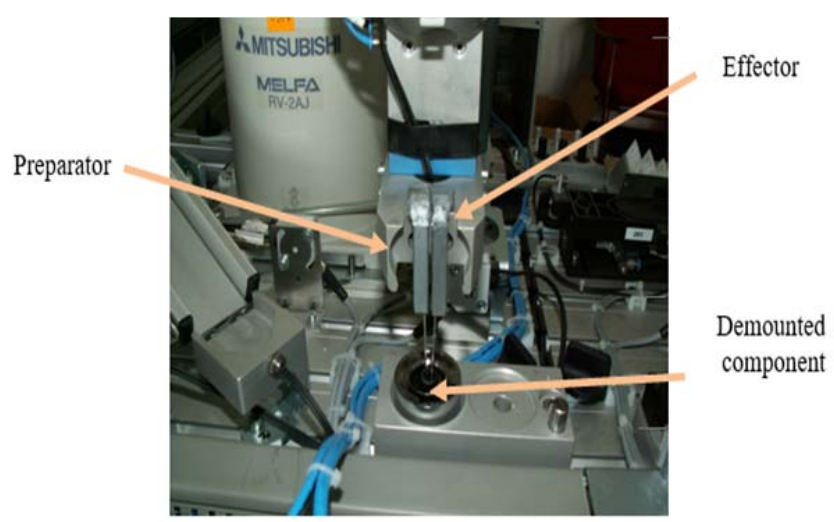

Figure 9. Placing the preparator on effector

The task is to create a program for dismantling this component. The problem arises when lifting the piston from the roller because the effector on the robot is not narrow enough to fit the cylinder 
diameter. This could be solved by creating a jig that the robot puts on the effector (Figure 9).

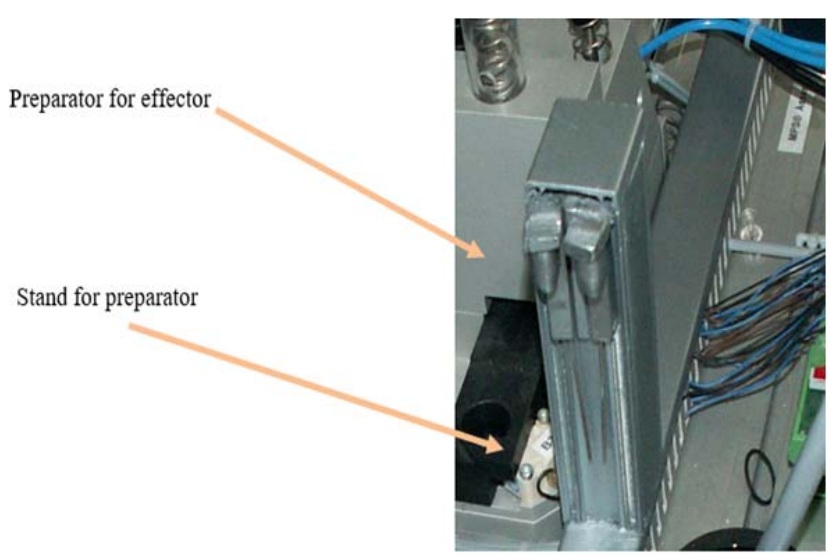

Figure 10. Preparator for effector in stand
This preparation consists of two parts - the jig itself, which consists of two pieces and a rack mounted on the assembly rail (Figure 10).

\subsection{Verification of Methodology}

The proposed methodology was verified on a real example (Figure 11). The robotized workplace was modelled and simulated with the task of removing the part by selecting it from the software library. We chose a robot type Mitsubishi RV 2AJ.

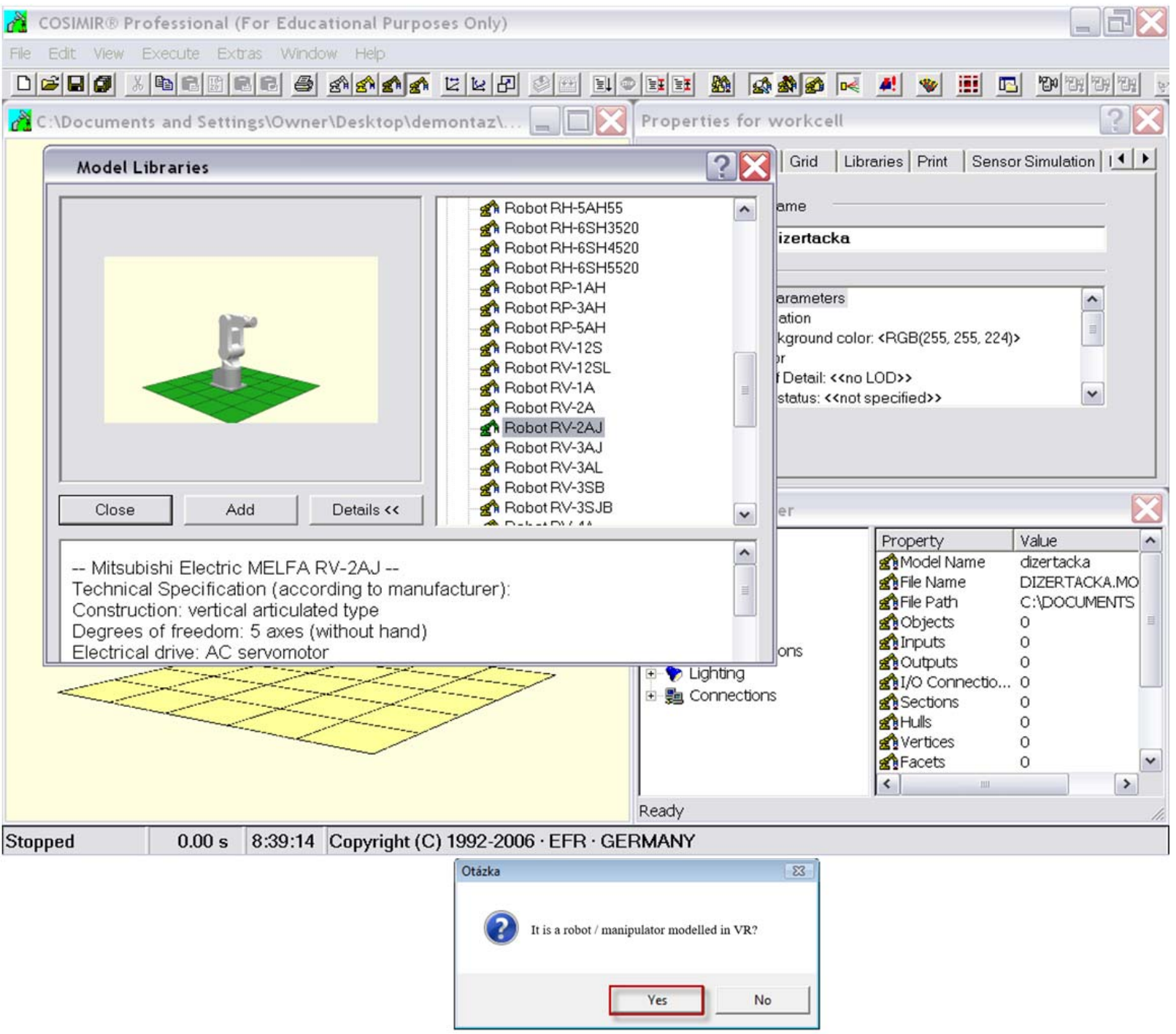

Figure 11. The "Question" dialog box and the library selection in Cosimir Professional Program 
Move in space, change position, orientation - the robot can be moved in Cosimir Professional in the
"Properties for object" window under "Position" (Figure 12).

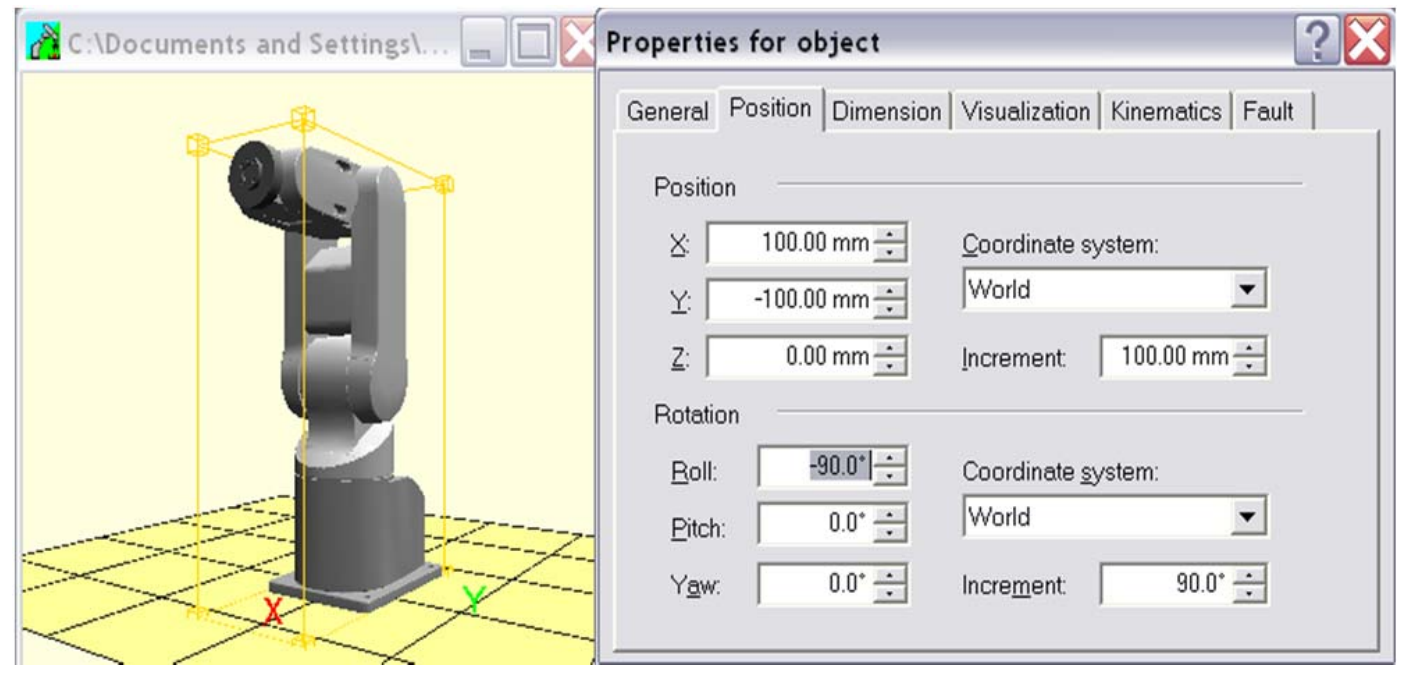

Figure 12. The "Recommendation" dialog box and the position change window for the robot

Implementation Successful - after such finetuning and re-testing of the robotized / assembly site, the site is ready for routine operation (Figure 13).

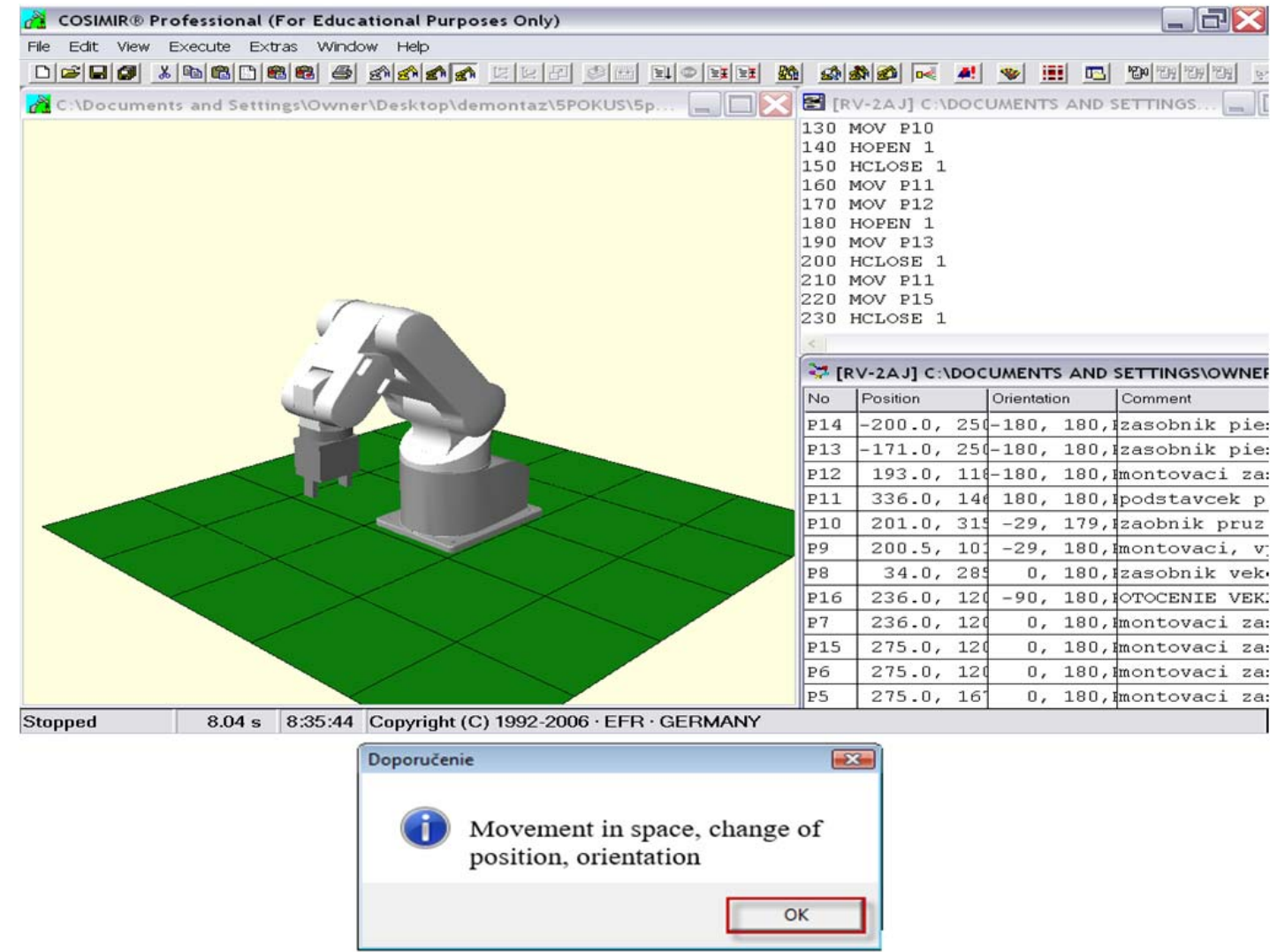

Figure 13. Simulated Mitsubishi RV 2AJ robot in Cosimir Professional Program

The task was solved using the proposed methodology for modelling and simulation of robotized / assembly workplaces. Using the methodology, the user passes point by point through the individual steps that lead it. The result was a successful implementation of the created program on a real workplace. Although in some places the methodology required more detailed thinking and knowledge on the part of the user. The user did not lose the direction of solution leading to a successful goal. 
The basis of the work was a well processed system analysis. In order to achieve objective conclusions, it was necessary to carry out system analysis in several areas (scientific disciplines) that directly concern the researched issue. It was necessary to carry out an interdisciplinary analysis. Subsequently, the actual methodology of robotized workplace modelling is designed, and its verification was realized by solving a specific robotized workplace.

\section{Conclusion}

The presented modelling methodology was successfully verified and used in a specific application. In no case was there any discrepancy or unclear logical link. Also, the local steps of the methodology were successfully applied locally.

Prolonged use of the methodology in industrial practice can bring with it further suggestions for its improvement. However, the methodology is not expected to require major changes in its structure and algorithms. Rather, it may be necessary to extend some steps (in the area of the simulation programs described) to make them more comprehensible to the selected group of users and up to date.

Effective use of the methodology assumes that its users will be educated in the relevant field. Thanks to the processing of the methodology into the form of dialog windows, the methodology is likely to find a quick way to users who work in the field of modelling and simulation of robotized workplaces.

\section{Acknowledgement}

This work has been supported by the Scientific Grant Agency of the Ministry of Education of the Slovak Republic (Project KEGA 032EU-4/2020 a KEGA 002TUKE-4/2020).

\section{References}

[1]. Bannat, A., Bautze, T., Beetz, M., Blume, J., Diepold, K., Ertelt, C., ... \& Zaeh, M. F. (2010). Artificial cognition in production systems. IEEE Transactions on automation science and engineering, 8(1), 148174.

[2]. Becker, F. D., \& Steele, F. (1995). Workplace by design: Mapping the high-performance workscape. Jossey-Bass.

[3]. Chryssolouris, G., Papakostas, N., \& Mavrikios, D. (2008). A perspective on manufacturing strategy: Produce more with less. CIRP Journal of Manufacturing Science and Technology, 1(1), 45-52.

[4]. Daneshjo, N., Olexova, C., Kralik, M., \& Danishjoo, E. (2019). An Algorithm in the Process of Planning of Safety Pathway-a Collision-Free Pathway of a Robot. Advances in Science and Technology. Research Journal, 13(3).

[5]. Ižol, P., Fabian, M., Kopas, M., \& Fedorko, G. (2013). Evaluation of machining strategies for production of free form surfaces using 3-axle milling. Manufacturing Technology, 13(4), 458-465.

[6]. Králik, M., \& Jerz, V. (2019). Solving Selected Problems with Ultrasonic Surface Strengthening of Metal Components. In Materials Science Forum (Vol. 952, pp. 22-28). Trans Tech Publications Ltd.

[7]. Makris, S., D. Mourtzis, \& Chryssolouris G. (2012). Computer Aided Manufacturing (CAM). In CIRP Encyclopedia of Production Engineering, edited by Luc Laperrière and Gunther Reinhart, 254-266. Berlin: Springer.

[8]. Palko, A., \& Smrcek, J. (2011). The use of pneumatic artificial muscles in robot construction. Industrial Robot: An International Journal, 38(1), 11-19.

[9]. Mihalíková, J., \& Líška, O. (2007). Work in simulation software Cosimir Professional In: Academic Journal of Manufactoring Engineering, Romania.

[10]. Rolón, M., \& Martínez, E. (2012). Agent-based modeling and simulation of an autonomic manufacturing execution system. Computers in industry, 63(1), 53-78.

[11]. Stanova, E., Fedorko, G., Fabian, M., \& Kmet, S. (2011). Computer modelling of wire strands and ropes Part I: Theory and computer implementation. Advances in Engineering Software, 42(6), 305-315.

[12]. Žlajpah, L. (2008). Simulation
robotics. Mathematics and
Simulation, $79(4), 879-897$. 